Received: 06.11.2019

Revised: 05.12.2019

Accepted: 20.12 .2019

DOI: $10.17804 / 2410-9908.2019 .6 .048-057$

\title{
FEATURES OF THE STRAIN-INDUCED DISSOLUTION AND STRUCTURE OF FRACTURE SURFACES IN Cu-Co ALLOYS
}

\author{
T. P. Tolmachev ${ }^{1,2,3, \text { a }^{*}}$, V. P. Pilyugin ${ }^{1,2, b)}$, A. M. Patselov ${ }^{1, c)}$, T. M. Gapontseva ${ }^{1,2, d)}$, \\ A. V. Plotnikov ${ }^{1,}$ e), R. V. Churbaev ${ }^{1, \text { f) }}$, and A. V. Inozemtsev ${ }^{1, g)}$ \\ ${ }^{1}$ M. N. Miheev Institute of Metal Physics, Ural Branch of the Russian Academy of Sciences, 18 S. Kovalevskoy St., Eka- \\ terinburg, 620108, Russia \\ ${ }^{2}$ B. N. Yeltsin Ural Federal University, 19 Mira St., Ekaterinburg, 620002, Russia \\ ${ }^{3}$ Institute of Engineering Science, Ural Branch of the Russian Academy of Sciences, 34 Komsomolskaya St., Ekaterin- \\ burg, 620049, Russia \\ a) (D) https://orcid.org/0000-0001-9073-4507; \\ b) (iD https://orcid.org/0000-0002-5150-6605; \\ c) (iD https://orcid.org/0000-0001-6438-0725; \\ d) (iD https://orcid.org/0000-0001-6101-1967; \\ e) (iD https://orcid.org/0000-0001-8949-5908; \\ f) (iD https://orcid.org/0000-0002-0085-1855; \\ g) (iD https://orcid.org/0000-0002-1737-6050 \\ "Corresponding author. E-mail: tolmachev@imp.uran.ru \\ Address for correspondence: ul. S. Kovalevskoy, 18, Ekaterinburg, 620108, Russian Federation \\ Tel.: +7 (343) 37838 05; fax: +7 (343) 3745244
}

$\mathrm{Cu}-\mathrm{Co}$ alloys containing various amounts of copper and cobalt have been synthesized by mechanical alloying at room temperature. The initial component ratio and the value of strain have an effect on the ultimate equilibrium solubility in the system, as well as on the fracture surfaces. The heterogeneity of fractures in the $\mathrm{Cu}-\mathrm{Co}$ alloys is revealed after the fracture of the alloys with a predominant content of $\mathrm{Co}$ and $\mathrm{Cu}$. An increase in strain leads to the formation of a uniformly distributed cleavage in a $\mathrm{Cu}$-based alloy, as well as in the case of originally equiatomic alloys. In addition, the formation of a solid solution based on high-temperature modification of Co has been found.

Keywords: mechanical alloying, severe plastic deformation, high-pressure torsion, X-ray diffraction analysis, scanning electron microscopy, supersaturated solid solution, immiscible $\mathrm{Cu}-\mathrm{Co}$ system.

\section{Acknowledgment}

The X-ray analysis was made in the laboratory of high-pressure physics, IMP UB RAS, Ekaterinburg. Electron microscopy was performed in the Nanotechnologies and Advanced Materials Testing Center, IMP UB RAS, Ekaterinburg.

The study was performed under a state assignment and supported by UB RAS, project No. 18-10-2-24.

\section{References}

1. Barabash O.M., Koval Yu.N. Struktura i svoystva metallov i splavov [Structure and Properties of Metals and Alloys]. Kiev, Naukova Dumka Publ., 1986, 599 p. (In Russian). 
2. Miedema A.R., De Chatel P.F., De Boer F.R. Cohesion in alloys - fundamentals of a semiempirical model. Physica B, 1980, vol. 100, pp. 1-28. DOI: 10.1016/0378-4363(80)90054-6.

3. Drits M.E., Budberg P.B., Burkhanov G.S., Drits A.M., and Panovko V.M. Svoystva elementov. Spravochnoe izdanie [Properties of Elements: A Reference Book, ed by M.E. Drits]. Moscow, Metallurgiya Publ., 1985. (In Russian).

4. Zhang X., Atrens A. A TEM study on the microstructure of rapidly solidified $\mathrm{Cu}-\mathrm{Co}$ alloys. Acta Metallurgica et Materialia, 1993, vol. 41, no. 2, pp. 563-568. DOI: 10.1016/09567151(93)90086-8.

5. Bridgman P.W. Effects of High Shearing Stress Combined with High Hydrostatic Pressure. Physical Review, 1935, vol. 48, pp. 825-847. DOI: 10.1103/PhysRev.48.825.

6. Edalati K., Horita Z. A review on high-pressure torsion (HPT) from 1935 to 1988. Materials Science and Engineering: A, 2016, vol. 652, pp. 325-352. DOI: 10.1016/j.msea.2015.11.074.

7. Glezer A., Kozlov E., Koneva N., Popova N., Kurzina I. Plastic Deformation of Nanostructured Materials, Boca Raton, CRC Press, 2017. DOI: 10.1201/9781315111964.

8. Straumal B.B., Kilmametov A.R., Korneva A., Mazilkin A.A., Straumal P.B., Zieba P., Baretzky B. Phase transitions in $\mathrm{Cu}$-based alloys under high pressure torsion. Journal of Alloys and Compounds, 2016, vol. 707, pp. 20-26. DOI: 10.1016/j.jallcom.2016.12.057.

9. Mazilkin A.A., Straumal B.B., Kilmametov A.R., Boll T., Baretzky B., Kogtenkova O.A., Korneva A., Ziкba P. Competition for impurity atoms between defects and solid solution during high pressure torsion. Scripta Materialia, 2019, vol. 173, pp. 46-50. DOI: 10.1016/j.scriptamat.2019.08.001.

10. Bachmaier A., Aboulfadl H., Pfaff M., Mbcklich F., Motz C. Structural evolution and strain induced mixing in $\mathrm{Cu}-\mathrm{Co}$ composites studied by transmission electron microscopy and atom probe tomography. Materials Characterization, 2015, vol. 100, pp. 178-191. DOI: 10.1016/j.matchar.2014.12.022.

11. Bachmaier A., Krenn H., Knoll P., Aboulfadl H., Pippan R. Tailoring the magnetic properties of nanocrystalline $\mathrm{Cu}-\mathrm{Co}$ alloys prepared by high-pressure torsion and isothermal annealing. Journal of Alloys and Compounds, 2017, vol. 725, pp. 744-749. DOI: 10.1016/j.jallcom.2017.07.200.

12. Tolmachev T.P., Pilyugin V.P., Patselov A.M., Ancharov A.I., Inozemtsev A.V. Mechanical Alloying and Fracture Features of Non-Equilibrium Cu-Co Alloys. Diagnostics, Resource and Mechanics of materials and structures, 2018, iss. 6, pp. 18-26. DOI: 10.17804/24109908.2018.6.018-026. URL: http://dream-journal.org/issues/2018-6/2018-6_235.html (accessed: 05.11.2019).

13. Tonkov, E.Yu. Fazovye diagrammy elementov pri vysokom davlenii [Elements Phase Diagrams under High Pressure]. Moscow, Nauka Publ., 1979, p. 192. (In Russian). 
Подана в журнал: 06.11.2019

УДК 669.35+669.25:539.89

DOI: $10.17804 / 2410-9908.2019 .6 .048-057$

\section{ОСОБЕННОСТИ ДЕФОРМАЦИОННОГО РАСТВОРЕНИЯ И СТРОЕНИЯ ПОВЕРХНОСТЕЙ РАЗРУШЕНИЯ СПЛАВОВ СИСТЕМЫ Сu-СО}

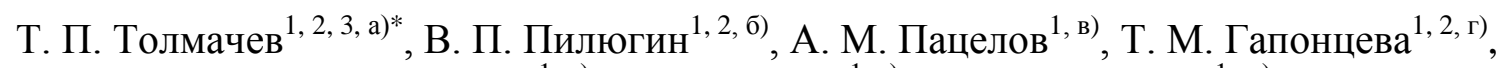
А. В. Плотников ${ }^{1, \text { д) }}$, Р. В. Чурбаев ${ }^{1, \text { е) }}$, А. В. Иноземцев ${ }^{1, \text { ж) }}$

${ }^{1}$ Институт физики металлов УрО РАН, Екатеринбург, Российская Федераџия
${ }^{2}$ Уральский федеральньй университет, Екатеринбург, Российская Федерация
${ }^{3}$ Институт машиноведения УрО РАН, Екатеринбург, Российская Федерация

a) (iD https://orcid.org/0000-0001-9073-4507;

б) (iD https://orcid.org/0000-0002-5150-6605;

в) (iD https://orcid.org/0000-0001-6438-0725;

г) (iD https://orcid.org/0000-0001-6101-1967;

д) (iD https://orcid.org/0000-0001-8949-5908;

e) (iD https://orcid.org/0000-0002-0085-1855;

ж) (iD https://orcid.org/0000-0002-1737-6050

*Ответственный автор. Электронная почта:

Адрес для переписки: ул. С. Ковалевской, 18, Екатеринбург, 620108, Российская Федерация

Тел.: +7 (343) 378-38-05; факс: (343) 374-52-44

Методом механосплавления при комнатной температуре синтезированы образцы сплавов системы $\mathrm{Cu}$-Со с различным содержанием меди и кобальта. В зависимости от исходного соотношения компонентов и величины деформации установлен факт изменения предельной равновесной растворимости в данной системе и изменение типа излома сплавов при его последующем разрушении. В результате разрушения сплавов с преимущественным содержанием Со и Сu выявляется неоднородность их изломов. Увеличение деформации приводит к формированию однородно распределенного скола в сплаве на основе $\mathrm{Cu}$, а также в случае сплавов с исходным эквиатомным соотношением исследуемых компонентов. Кроме того, установлено формирование твердого раствора на основе высокотемпературной модификации Сo.

Ключевые слова: механическое сплавление, большие пластические деформации, кручение под высоким давлением, рентгеновская дифрактометрия, сканирующая электронная микроскопия, пересыщенный твердый раствор, система ограниченной растворимости Cu-Co.

\section{1. Введение}

Сплавы из компонентов, обладающих ограниченной растворимостью, имеют большое значение как в научном, так и технологическом аспектах. Система $\mathrm{Cu}-\mathrm{Co}$ характеризуется положительной энтальпией смешения компонентов, их ограниченной растворимостью: даже при $800{ }^{\circ} \mathrm{C}$ растворимость кобальта составляет не более 3 ат. \%, а растворимость меди не более 1,5 ат. \% $[1,2]$. Разница ионных радиусов компонентов составляет более $15 \%$ [3]. Определение условий формирования, а также исследование структуры и механических свойств сплавов системы Сu-Со в концентрациях существенно превышающих равновесное состояние, необходимы для создания основы реметаллических присадок как восстановителей поврежденных поверхностей в высоконагруженных парах трения, а также сплавов с повышенными прочностью и коррозионной стойкостью [4]. Используемые для синтеза неравновесных сплавов методы экстремального воздействия, такие как быстрая закалка, шаровой по- 
мол, взрывная обработка и др., позволяют получать материал в дисперсном виде, что не дает возможность изучить пластичность, твердость и характерный тип разрушения образцов, поскольку после названных обработок они имеют порошковое состояние.

Для решения данной задачи целесообразно получать образцы в цельном виде при контролируемых условиях по температуре, скорости и величине деформации, что возможно в методе сдвига в камере Бриджмена под высоким давлением (кручением под высоким давлением - КВД) [5-6].

Рассматриваемая система в качестве объекта изучения влияния больших пластических деформаций на структуру и свойства привлекает к себе внимание ряда ведущих профильных лабораторий [8, 9-11]. Авторами статьи [12] было проведено механическое сплавление порошковых меди и кобальта методом КВД на одинаковую величину деформации для трех составов шихты. Было установлено, что изменение соотношения компонентов в шихте существенным образом влияет на характерный тип разрушения, связанный с различной полнотой протекания процессов механосплавления. Предполагалось, что одним из путей реализации завершенности механосинтеза может выступать повышение величины деформации.

Таким образом, основные цел исследования - выявление особенностей исходно порошковых компонентов Со и Сu различных составов, изучение кинетики процессов деформационно-индуцированного синтеза и микроструктуры поверхностей изломов полученных сплавов.

\section{2. Материал и методика}

Компоненты перед механосплавлением представляли собой порошки меди (чистотой 99,97 \%) и кобальта (чистотой 99,98 \%) с размером частиц не более 100 мкм в трех соотношениях: $\mathrm{Cu} 20 \mathrm{Co} 80, \mathrm{Cu} 50 \mathrm{Co} 50, \mathrm{Cu} 80 \mathrm{Co} 20$, ат. \%. Процедура механического сплавления заключалась в применении метода КВД на 5 и 30 об. наковален Бриджмена. В результате получали образцы дискообразной формы диаметром 5 мм и средней толщиной 0,05 мм. Температура обработки составляла $300 \mathrm{~K}$, давление - 8 ГПа, скорость вращения наковален 1 об./мин. Структурный и фазовый анализ образцов до деформации и после нее проводили с помощью метода рентгеновской дифрактометрии в геометрии на отражение на аппарате ДРОН-3 в СuК $\alpha$-излучении. Образцы синтезированных КВД сплавов разрушали по диаметру изгибным способом и получали изображения поверхностей разрушения с помощью сканирующего электронного микроскопа Quanta-200. Более подробное описание методик приготовления и исследования сплавов в работе [12].

\section{3. Результаты и обсуждение}

В результате КВД Сu и Со в исходно порошковом состоянии и в трех соотношениях компонентов были сформированы образцы сплавов в цельном виде. На дифрактограмме от порошковой смеси $\mathrm{Cu}$ и $\mathrm{Co}$, взятых в соотношении $\mathrm{Cu} 50 \mathrm{Co} 50$, ат. \%, выделяются пики от меди и присутствуют пики от ГПУ-кобальта (рис. 1, дифрактограмма 1). Для более наглядного представления о фазовых и структурных изменениях в деформированных образцах данные приведены в диапазоне 2theta углов дифракции $38-55^{\circ}$.

КВД на 5 об. наковальни приводит к значительному уширению пиков компонентов на дифрактограммах 2-4 по сравнению с исходным порошковым состоянием (дифрактограмма 1), а также к снижению интенсивностей вторых и последующих пиков относительно (111) ГЦК-фазы (рис. 1). Интенсивность ряда пиков от ГПУ-фазы также претерпевает изменение. Так, в результате КВД смеси исходного состава Сu20Co80, ат. \%, пик $(00,2)$ становится выше соседнего пика $(10,1)$ (дифрактограмма 2). Для составов смеси Сu50Co50 и $\mathrm{Cu} 80 \mathrm{Co} 20$, ат. \%, пики от ГПУ-фазы на основе низкотемпературной модификации кобальта становятся практически неотделимыми от фона (дифрактограммы 3 и 4). Таким образом, 
в результате, как деформации, так и увеличения доли кобальта в шихте происходит уменьшение областей когерентного рассеяния и увеличение внутренних напряжений.

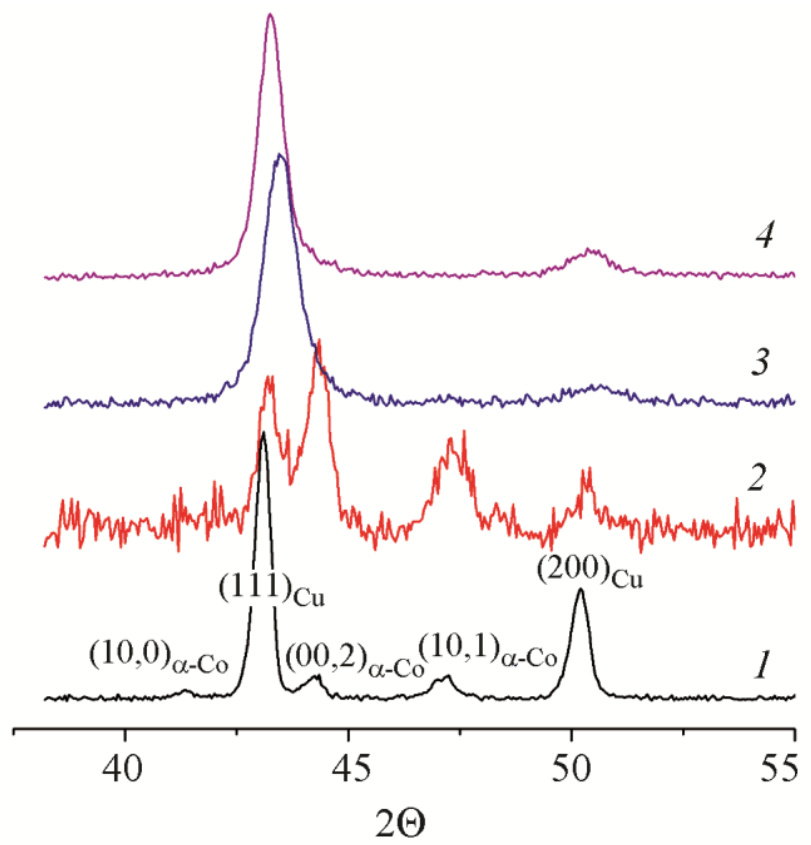

Рис. 1. Рентгеновские дифрактограммы компонентов системы $\mathrm{Cu}$ и Со в порошковом состоянии и после механосплавления: 1 - недеформированная смесь состава Cu50Co50, ат. \%. После КВД на 5 об.: 2 - состава Cu20Co80, ат. \%; 3 - Cu50Co50, ат. $\% ; 4-\mathrm{Cu} 80 \mathrm{Co} 20$, ат. $\%$

Кроме того, КВД привело не только к изменению формы и интенсивностей пиков на дифрактограммах сплавов $\mathrm{Cu}-\mathrm{Co}$, но и к смещению пиков от ГЦК-фазы в сторону больших углов дифракции (рис. 1). Этот эффект тем больше, чем больше доля кобальта в шихте. Смещение рефлексов вместе с уменьшением интенсивности рефлексов от кобальта связано с его деформационным растворением (по крайней мере, частичным) в матрице меди по типу замещения.

Увеличение угла поворота до 30 об. приводит к еще большему увеличению ширины рефлексов на дифрактограммах 2-4 (рис. 2), что свидетельствует об увеличении микронапряжений и уменьшении размеров областей когерентного рассеяния. Присутствуют только пики от ГЦК-фазы, присутствие линий ГПУ-фазы наблюдается только на уровне фона. Дальнейшее смещение ГЦК-пиков в сторону увеличения угла 2theta дифракции также имеет место.

Визуально, построив дифрактограмму деформированного на 30 об. образца из смеси исходного состава $\mathrm{Cu} 20 \mathrm{Co} 80$, ат. \% (рис. 2), можно оценить индуцированный обработкой переход, расположив тут же рефлексы от структур меди и высокотемпературной модификации кобальта, обладающий ГЦК-решеткой, по литературным данным. Наиболее четко различим пик, расположенный между положениями рефлексов (111) от чистых меди и ГЦК-кобальта.

Хотя в целом уровень фона достаточно высок, в местах, расположенных между остальными пиками чистых компонентов (в пределах углов 2theta дифракции до 100 градусов), за исключением пиков (200) и (222), имеются слабо выраженные достаточно широкие пики от деформированной структуры. Таким образом, визуальная оценка говорит о формировании ГЦК-фазы твердого раствора из меди и кобальта. 


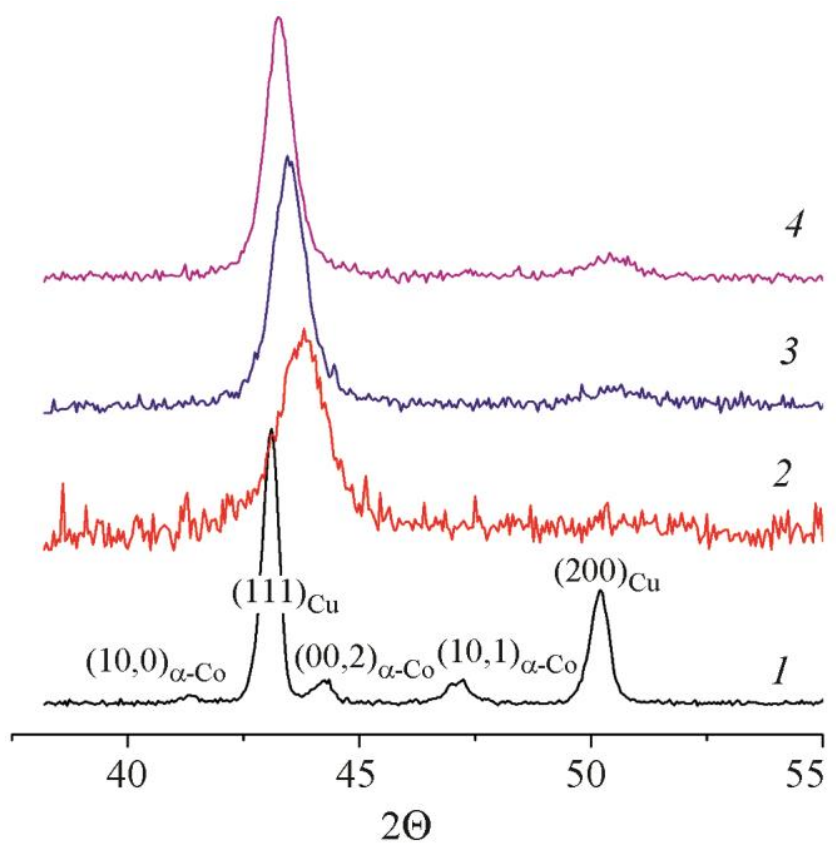

Рис. 2. Рентгеновские дифрактограммы компонентов системы $\mathrm{Cu}$ и Со в порошковом состоянии и после механосплавления: 1 - недеформированная смесь состава Cu50Co50, ат. \%. После КВД на 30 об.: 2 - состава Cu20Co80, ат. \%; $3-\mathrm{Cu} 50 \mathrm{Co} 50$, ат. $\% ; 4-\mathrm{Cu} 80 \mathrm{Co} 20$, ат. $\%$

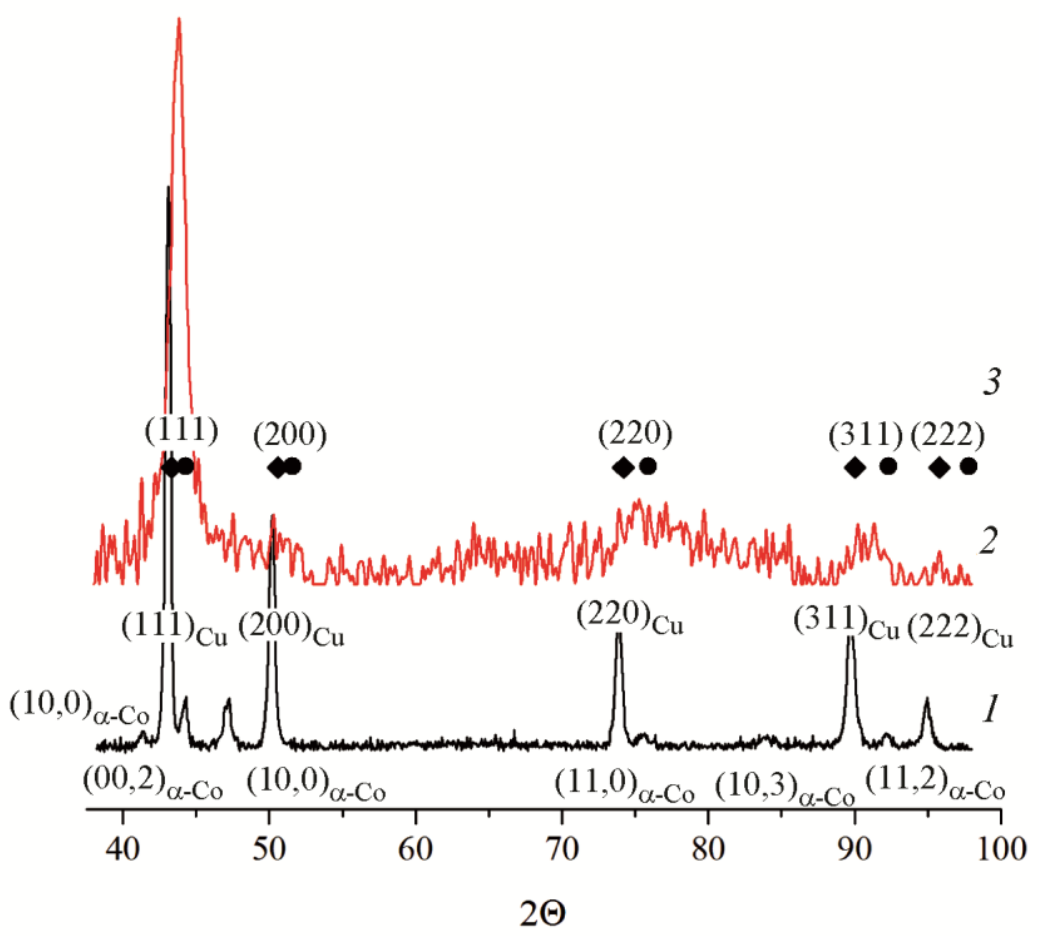

Рис. 3. Рентгеновские дифрактограммы: 1 - от порошковой смеси в эквиатомном соотношении компонентов; 2 - от синтезированного КВД на 30 об. образца исходного состава $\mathrm{Cu} 20 \mathrm{Co} 80$, ат.\%; 3 - литературные данные по рефлексам от меди (४) и высокотемпературной фазы кобальта

Расчет периода кристаллической решетки исходного состояния показывает, что значения периода отличаются от табличных значений $(3,615-3,617 \AA[1,3])$. Более того, отли- 
чаются и таковые значения от порошковой меди (таблица). Это можно объяснить мелкодисперсностью частиц, вероятным наличием примесей по типу оксидной пленки, а также предварительной обработкой перед КВД для гомогенизации смеси. Тем не менее, различия в значениях периода кристаллической решетки ГЦК-фаз составляют сотые доли ангстрема.

Значения периодов кристаллической решетки меди в исходном состоянии и ГЦК-твердого раствора

\begin{tabular}{|c|c|c|c|}
\hline $\begin{array}{c}\text { Число оборотов } \\
\text { наковальни }\end{array}$ & Сu80Со20, ат. \% & Сu50Со50, ат. \% & Cu20Со80, ат. \% \\
\cline { 1 - 4 } Исходное состояние & $a_{\mathrm{cp}}($ ГЦК), $\AA$ & $a_{\mathrm{cp}}($ ГЦК $), \AA$ & $a_{\mathrm{cp}}($ ГЦК), $\AA$ \\
\hline$n=5$ & 3,620 & 3,625 & 3,623 \\
\hline$n=30$ & 3,617 & 3,598 & 3,587 \\
\hline
\end{tabular}

Уменьшение значений периодов кристаллической решетки ГЦК-фазы на основе меди показывает о постепенном растворении кобальта в медной матрице с ростом деформации и увеличении содержания кобальта в шихте, что подтверждает данные визуальной оценки положения и формы пиков на дифрактограммах. Известно, что в данной системе постепенное растворение кобальта в матрице меди будет приводить к уменьшению периода кристаллической решетки твердого раствора [3], что будет отвечать смещению пиков от фазы на основе меди в сторону больших углов дифракции. Кроме того, уже в результате деформации на 5 об. наковальни преодолевается пороговое значение в $3,607 \AA$, которое соответствует максимально возможной растворимости в 8 ат. \% Со при $1110{ }^{\circ} \mathrm{C}$ на равновесной фазовой диаграмме $\mathrm{Cu}-\mathrm{Co}[3]$.

Для изучения характера разрушения, а также структурного состояния в объеме полученных деформацией сплавов, образцы, имеющие форму дисков, подвергали изгибному излому по диаметру. Образец сплава исходного состава $\mathrm{Cu} 20 \mathrm{Co} 80$, ат. \%, деформированный на 5 об. наковальни, имеет весьма неоднородную поверхность разрушения (рис. $4 a, n=5$ ).

На нем как визуально, так и по анализу характеристического излучения можно определить частицы недорастворившегося чистого кобальта и образовавшегося твердого раствоpa (рис. 4 a). В результате увеличения числа оборотов до 30 характер излома сплава существенно меняется. Участки, содержащие частицы недорастворенных компонентов отсутствуют, рельеф менее выражен в сравнении с рельефом предыдущего образца (рис. $4 a, n=$ 30). На изломе различимы две неравные области. Первая находится вблизи торцевых граней образца, располагавшихся во время КВД на рабочих площадках наковален. Характер излома в данной области - скол, прерываемый единичными ямками и ручьистыми бороздами, идущими от внешней поверхности вглубь образца по пути формирования излома при изгибном воздействии. Поверхность вблизи противоположной стороны образца имеет аналогичный характер разрушения, но меньшую площадь. В объеме образца излом имеет иной характер по сравнению с приповерхностными областями. Отмечается слоистость, параллельная плоскости образца, с вытянутыми элементами структуры. Имеются единичные большие глубокие трещины под острым углом друг к другу, располагающиеся вдоль плоскости образца. Также имеются тонкие трещины, разделяющие слои, которые могут быть хорошо различимы только при больших увеличениях.

Излом от образца эквиатомного состава (рис. 4 б) отличается от излома образца состава $\mathrm{Cu} 20 \mathrm{Co} 80$, ат. \% однородным типом поверхности разрушения, аналогичным излому боковых приповерхностных участков. Тип поверхности излома одинаков как после 5 , так и после 30 об. наковальни. 


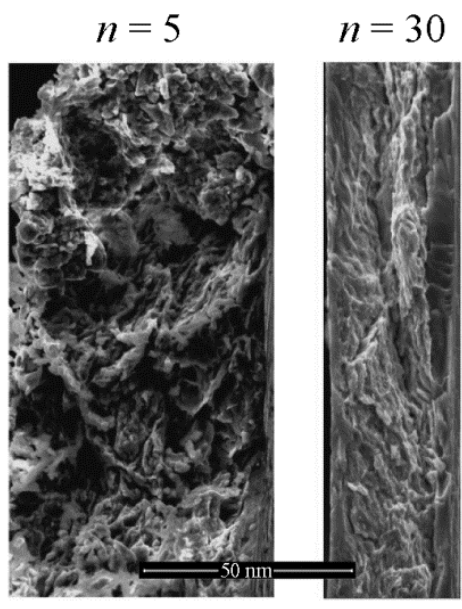

$a$

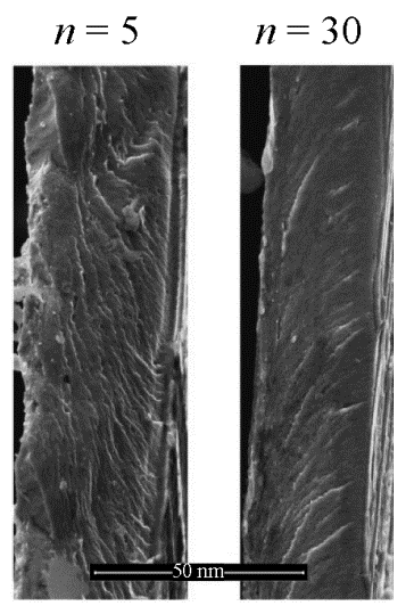

6

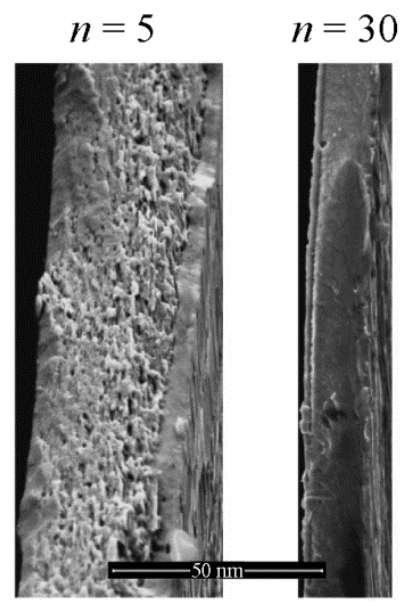

B

Рис. 4. Изображения в СЭМ изломов механически синтезированных сплавов системы Сu-Со на расстоянии 0,5 радиуса, полученных КВД на 5 и 30 об. в наковальни: $a$ - исходный состав Сu20Co80, ат. \%; $\sigma$ - Cu50Co50, ат. \%; в-Cu80Co20, ат. \%

На изломе образца, полученного деформацией на 5 оборотов наковальни исходного соотношения компонентов в шихте Cu80Co20, ат. \% (рис. 4 в), также выявляются два типа поверхности разрушения: приповерхностные области и центральная область, ограниченная приповерхностными. Области, более близкие к наковальням, в процессе обработки испытали значительно большую деформационную проработку структуры, вследствие чего образовался сплошной, ровный излом по типу хрупкого скола. В то же время в центральной области (рис. 3 в, $n=5$ ) имеются участки, которые подверглись меньшей деформационной обработке. На изображениях образцов после 30 об. (рис. 4 в) такие изломы отсутствуют.

Таким образом, в зависимости от соотношения меди и кобальта в шихте изменяется тип излома механосинтезированного сплава: хрупко-вязкий (рис. 4 в) в случае состава $\mathrm{Cu} 80 \mathrm{Co} 20$, ат. \%; хрупкий по типу скола; однородный и равномерный по рельефу поверхности в случае эквиатомного состава; смешанного типа в случае пропорции $\mathrm{Cu} 20 \mathrm{Co} 80$, ат. \%. Увеличение числа оборотов наковальни, приводит в случае соотношения компонентов $\mathrm{Cu} 20 \mathrm{Co80}$, ат. \% к излому сплава с менее выраженной неоднородностью, хрупким характером разрушения. В случае эквиатомного соотношения ситуация существенно не меняется, а для состава Сu80Co20, ат. \% излом становится более однородным.

Оценка состава сформировавшегося твердого раствора показывает, что для сплава с исходным составом Сu80Сo20, ат. \% в результате увеличения числа оборотов КВД формируется твердый раствор на основе меди с малой долей кобальта на уровне нескольких процентов (рис. 5). Для смеси рассматриваемых компонентов эквиатомного состава деформационное растворение кобальта в медной матрице составляет уже более 10 ат. \%. КВД состава $\mathrm{Cu} 20 \mathrm{Co80}$, ат. \% приводит к формированию твердого раствора с еще большим содержанием доли кобальта, чем в предыдущих случаях, а увеличение числа оборотов приводит к формированию ГЦК-твердого раствора на основе кобальта (рис. 5). 


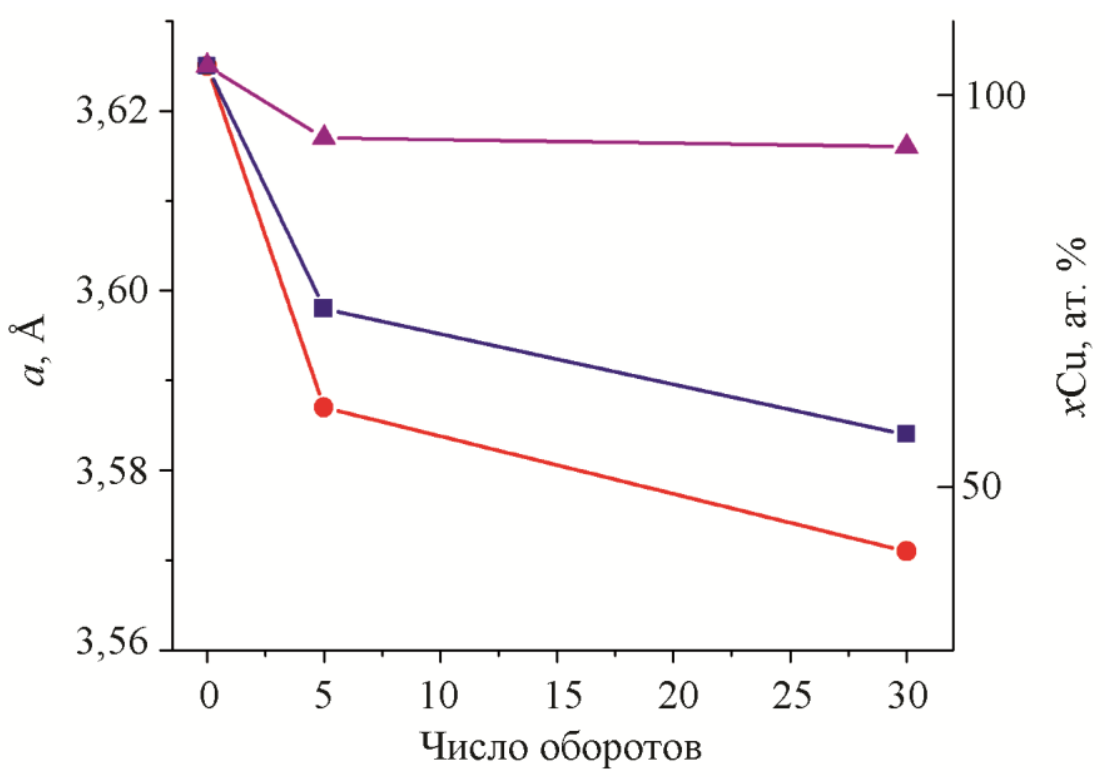

Рис. 5. Изменение периода кристаллической решетки и состава ГЦК-твердого раствора на основе меди и кобальта в зависимости от числа оборотов КВД смесей компонентов в исходном соотношении: $\mathrm{Cu} 80 \mathrm{Co} 20$, ат. \% ( $\mathbf{\Delta}$ ); Cu50Co50, ат. \% (汭; Cu20Co80, ат. \% (•)

Отметим, что температура полиморфного превращения в кобальте начинается выше $400{ }^{\circ} \mathrm{C}$ и возрастает с ростом давления [13], поэтому только за счет возрастания давления формирование ГЦК-фазы на основе кобальта при комнатной температуре не представляется возможным. Наличие высокого давления необходимо, но не достаточно. Решающим фактором является деформация и индуцированные ей процессы, такие как диффузия под напряжением, деформационная фрагментация (более подробно - в работе [12]), приводящие к взаимному перемешиванию атомов компонентов системы $\mathrm{Cu}-\mathrm{Co}$.

Таким образом, достигается не только превышение границы равновесной (в т.ч. высокотемпературной) растворимости, но и происходит формирование ГЦК-твердого раствора в системе $\mathrm{Cu}-\mathrm{Co}$, но уже на основе высокотемпературной в-модификации кобальта. Учет характера разрушения позволяет заключить, что для состава Cu20Co80, ат. \% все указанное касается приповерхностных областей, тогда как в объеме имеется незавершенность процессов механосплавления в сравнении со сплавами других исходных составов.

\section{4. Заключение}

В системе «медь-кобальт» установлено формирование пересыщенных твердых растворов в результате воздействия больших пластических деформаций методом кручения под высоким квазигидростатическим давлением на наковальнях Бриджмена. Достигается не только выход за пределы равновесной растворимости по фазовым диаграммам, но и формирование твердого раствора замещения на основе ГЦК-кобальта. Для повышения однородности распределения твердого раствора по всему объему сплава необходимо идти по пути возрастания величины деформации, а также рассматривать изменение других физических параметров механосплавления.

\section{Благодарность}

Рентгеновский анализ выполнен на базе Лаборатории физики высоких давлений ИФМ УрО РАН, г. Екатеринбург. Электронная микроскопия выполнена в ЦКП «Испытательный иентр нанотехнологий и перспективных материалов», ИФМ УрО РАН, г. Екатеринбург.

Работа выполнена при поддержке проекта УрО РАН (проект № 18-10-2-24) и в рамках государственного задания. 


\section{Список литературы}

1. Барабаш О. М., Коваль Ю. Н. Структура и свойства металлов и сплавов. - Киев : Наукова думка, 1986. - 599 с.

2. Miedema A. R., De Chatel P. F., De Boer F. R. Cohesion in alloys - fundamentals of a semi-empirical model // Physica B. - 1980. - Vol. 100. - P. 1-28. - DOI: 10.1016/03784363(80)90054-6.

3. Свойства элементов : справочник / М. Е. Дриц, П. Б. Будберг, Г. С. Бурханов, А. М. Дриц, В. М. Пановко / под ред. М. Е. Дрица. - М. : Металлургия, 1985 - 672 с.

4. Zhang X., Atrens A. A TEM study on the microstructure of rapidly solidified Cu-Co alloys // Acta Metallurgica et Materialia. - 1993. - Vol. 41, no. 2. - P. 563-568. - DOI: 10.1016/09567151(93)90086-8.

5. Bridgman P. W. Effects of High Shearing Stress Combined with High Hydrostatic Pressure // Physical Review. - 1935. - Vol. 48. - P. 825-847. - DOI: 10.1103/PhysRev.48.825.

6. Edalati K., Horita Z. A review on high-pressure torsion (HPT) from 1935 to 1988 // Materials Science and Engineering: A. - 2016. - Vol. 652. - P. 325-352. - DOI: 10.1016/j.msea.2015.11.074.

7. Основы пластической деформации наноструктурных материалов / А. М. Глезер, Э. В. Козлов, Н. А. Конева, Н. А. Попова, И. А. Курзина / под ред. А. М. Глезера - М. : Физматлит, 2016. - 304 с. - ISBN: 978-5-9221-1689-3.

8. Phase transitions in Cu-based alloys under high pressure torsion / B. B. Straumal, A. R. Kilmametov, A. Korneva, A. A. Mazilkin, P. B. Straumal, P. Zieba, B. Baretzky // Journal of Alloys and Compounds. - 2016. - Vol. 707. - P. 20-26. - DOI: 10.1016/j.jallcom.2016.12.057.

9. Competition for impurity atoms between defects and solid solution during high pressure torsion / A. A. Mazilkin, B. B. Straumal, A. R. Kilmametov, T. Boll, B. Baretzky, O. A. Kogtenkova, A. Korneva, P. Ziкba // Scripta Materialia. - 2019. - Vol. 173. - P. 46-50. - DOI: 10.1016/j.scriptamat.2019.08.001.

10. Structural evolution and strain induced mixing in $\mathrm{Cu}-\mathrm{Co}$ composites studied by transmission electron microscopy and atom probe tomography / A. Bachmaier, H. Aboulfadl, M. Pfaff, F. Mьcklich, C. Motz // Materials Characterization. - 2015. - Vol. 100. - P. 178-191. DOI: 10.1016/j.matchar.2014.12.022.

11. Tailoring the magnetic properties of nanocrystalline $\mathrm{Cu}-\mathrm{Co}$ alloys prepared by high-pressure torsion and isothermal annealing / A. Bachmaier, H. Krenn, P. Knoll, H. Aboulfadl, R. Pippan // Journal of Alloys and Compounds. - 2017. - Vol. 725. - P. 744-749. - DOI: 10.1016/j.jallcom.2017.07.200.

12. Mechanical Alloying and Fracture Features of Non-Equilibrium Cu-Co Alloys / T. P. Tolmachev, V. P. Pilyugin, A. M. Patselov, A. I. Ancharov, A. V. Inozemtsev // Diagnostics, Resource and Mechanics of materials and structures. - 2018. - Iss. 6. - P. 18-26. DOI: 10.17804/2410-9908.2018.6.018-026. - URL: http://dream-journal.org/issues/2018-6/20186_235.html (accessed: 05.11.2019).

13. Тонков Е. Ю. Фазовые диаграммы элементов при высоком давлении. - М. : Наука, Главная редакция физико-математической литературы, 1979. - 192 с. 